Background Vascular changes are consistent early findings in SSc and often proceed the development of fibrosis. Despite a severe reduction in the capillary density, signs of neoangiogenesis cannot be detected.

Objectives To examine the role of VEGF and its receptors in the impaired angiogenesis of SSc.

Methods Skin pO2 was measured intradermally using the pO2 histograph in 13 patients with SSc and in 5 healthy controls. Cultured SSc and normal skin fibroblasts were exposed to hypoxia and analysed for VEGF mRNA by real-time PCR (TaqMan). Immunohistochemistry with anti-VEGF-Receptor-1 and antiVEGF-Receptor-2 antibodies was performed on skin biopsies of SSc patients and healthy controls. Serum samples of 47 patients with SSc and 21 healthy controls were analysed for VEGF by ELISA and correlated with clinical parameters.

Results PO2 values from involved skin of SSc patients $(23,7 \pm$ $2,1 \mathrm{mmHg}$ ) were significantly lower compared to healthy controls $(33,6 \pm 4,1 \mathrm{mmHg})$ and non-involved skin areas $(37,8 \pm$ $8,6 \mathrm{mmHg}, \mathrm{p}<0.05)$. After hypoxic exposure of cultured fibroblasts, VEGF mRNA was found to be upregulated compared to normoxic controls in SSc (3,7 $\pm 1,7$ fold) and normal skin fibroblasts $(3,0 \pm 1,8$ fold). The bioavailability of VEGF was not reduced, since the expression of VEGF-Receptor-1 and VEGFReceptor- 2 was found on endothelial cells of $4 / 5$ patients with SSc, whereas no signal could be detected in healthy controls. In addition to the overexpression of VEGF mRNA in skin samples, serum levels of VEGF protein were significantly higher in SSc patients compared to healthy controls (mean $461 \mathrm{pg} / \mathrm{ml}$, range 93-1153 pg/ml vs. $106 \mathrm{pg} / \mathrm{ml}$, range $0-500 \mathrm{pg} / \mathrm{ml}, \mathrm{p}<0.001)$. Interestingly, levels of VEGF were upregulated in patients with pre-SSc (clinical evidence for SSc without fulfilling ACR criteria, mean $451 \mathrm{pg} / \mathrm{ml}$, range $230-601 \mathrm{pg} / \mathrm{ml}, \mathrm{p}<0.05)$ and in patients with early disease stages (disease duration $<2$ years, mean $569 \mathrm{pg} / \mathrm{ml}$, range $135-1013 \mathrm{pg} / \mathrm{ml}, \mathrm{p}<0.01$ ). Patients with diffuse disease and the presence of fingertip ulcers had higher levels of VEGF (mean $339 \mathrm{pg} / \mathrm{ml}$, range 93-714 pg/ml) than healthy controls, but highly significant lower levels than patients without fingertip ulcers (mean 655 pg/ml, range 281$1151 \mathrm{pg} / \mathrm{ml}, \mathrm{p}<0.001)$.

Conclusion Our results suggest a hypoxia mediated activation of the VEGF/VEGF-receptor axis in SSc. The correlation with clinical parameters indicate that elevated levels of VEGF are a feature of early disease stages and might be protective against the development of fingertip ulcers. Since the feasibility of a treatment with VEGF has just been approved in other ischaemic diseases, the application of VEGF may be a therapeutic option for the vascular insufficiency in SSc.

\section{Sjoegren's syndrome}

\section{AB0117 SALIVA IN PATIENTS WITH DIFFERENT RHEUMATIC DISEASES}

M Helenius, JH Meurman, I Helenius, K Kari, J Hietanen, R Suuronen, H Kautiainen, M Leirisalo-Repo, C Lindqvist. Department of Medicine, Meilahti Hospital, Helsinki, Finland

\subsection{6/annrheumdis-2001.300}

Background Rheumatic diseases affect salivary glands. ${ }^{1}$ However, data is sparse on saliva of patients with different disease subgroups with expected differencies.
Objectives We studied salivary flow and biochemistry in 22 patients with spondyloarthropathy (SPA), 19 with ankylosing spondylitis (AS), 25 with rheumatic arthritis (RA) and 19 with mixed connective tissue disease (MCTD) and 85 age- and sexmatched controls. The mean age was 44.5 years and duration of disease 10.5 years.

Methods Minor salivary gland biopsies were taken for inflammatory focus score, and salivary components analysed biochemically. $^{2}$

Results The results showed an inverse correlation between focus scores and decreased salivary flow rates $(\mathrm{R}=-0.48$, CI 0.64 0.29 for resting flow, $\mathrm{R}=-0.49$, CI $0.65-0.30$ for stimulated flow). Compared with controls, decreased resting flow $(<0.1$ $\mathrm{mL} / \mathrm{min})$ was most frequent in AS group $(22 \%$ vs. $0 \%, \mathrm{p}<$ $0.05)$, while decreased stimulated flow $(<0.7 \mathrm{~mL} / \mathrm{min})$ was most frequent in the MCTD group (60\% vs. $16 \%, \mathrm{p}<0.05)$. Lower concentrations of salivary amylase $(p<0.001)$, but higher albu$\min (\mathrm{p}<0.01)$, total protein $(\mathrm{p}<0.001), \operatorname{IgA}(\mathrm{p}<0.05), \operatorname{IgG}$ $(\mathrm{p}<0.001)$ and $\operatorname{IgM}(\mathrm{p}<0.001)$ were found in the patients.

Conclusion Thus, the hypothesis was confirmed showing significant differences in salivary parameters between patients and controls, and also differences between the patients with various rheumatic diseases.

\section{REFERENCES}

1 Daniels. Scand J Rheum. 1986;61:36-43

2 Pajukoski, et al. Oral Surg. 1997;84:265-71

\section{AB0118 SUPRA-NUCLEAR OPHTALMOPLEGIA IN PRIMARY SJÖGREN'S SYNDROME}

${ }^{1} \mathrm{~B}$ Mugnier, ${ }^{2} \mathrm{~F}$ Nicoli, ${ }^{1} \mathrm{JP}$ Mattei. ${ }^{1}$ Service de Rhumatologie; ${ }^{2}$ Centre de Résonance Magnétique Et Biologie Médicale, Faculté de La Timone, Marseille, France

10.1136/annrheumdis-2001.301

\section{Background}

Objectives Neurological manifestations involving the central and the peripheral nervous systems (CNS, PNS) are observed in $10 \%-32 \%$ of patients with primary Sjögren's syndrome (pSS). If the lesions of the PNS have been perfectly described, data on CNS involvement in pSS, as for it, is controversial with regard in significance and aetiology. On occasion of an exceptional supra-nuclear ophtalmoplegia during pSS, we discuss relevance of CNS involvement in pSS.

Methods

Results A 61 year-old-woman encompassed several episodes of neurologic involvement resolving completely without any treatment: twice it consisted of mied nerves involvement (dysphagia) and dysaesthesia in the trigeminal territories and four times of supra-nuclear ophtalmoplegia with typical palsy of volontary lateral and vertical gaze compensated for oculo-cephalics reflexes. Repeated cerebral investigations excluded multiple sclerosis and vascular lesions. The absence of hypertonia, akinesia, or frontal syndrome associated to opthtalmoplegia, despite several years duration, reduces the probability of a Steele-Richardson disease. Neurologic signs onset began sixteen years before the diagnosis of pSS (grade III histologic lesions on minor salivary gland biopsy). Biochemical, immunologic and histological investigations did not reveal any other connective tissue disorders.

This is the first case of supra-nuclear ophtalmoplegia developped in such a context. Oculo-motors troubles like nystagmus, ocular palsy, cerebellar syndrome and even internuclear ophtalmoplegia has been describe during pSS. Internuclear 
ophtalmoplegia is provoked by intra-axial lesions within the higher part of the cerebral trunk, above mesencephalic oculomotor centres; however, a supra-nuclear lesion during pSS has never been reported so far.

Through a literature review, we discuss relevance, aetiology and treatment of CNS involvement in pSS. Data are imprecise and even contradictory. Frequency of CNS involvement in pSS could vary from $0 \%$ to $25 \%$ and might display various patterns: focal or multi focal lesions entailing encephalon, cerebral trunk, cerebellum or medulla, but also more diffuse processes as an aseptic meningo-encephalitis or as a cognitive impairment.

It's pathogenesis is poorly understood. Two mechanisms have been proposed: the first being of an ischaemic nature resulting from a vasculitis of small brain vessels, the second through an autoimmune response (humoral by anti-neuronal antibodies or cytotoxic).

There is no clear consensus concerning the treatment of neurological complications of pSS. Corticosteroïds are usually initiated first; immuno-suppressive agents may be necessary in the absence of improvement.

Conclusion A supranuclear ophtalmoplegia can be observed in pSS; it reinforces the thesis of a CNS involvement in this connective disease, in so far such a characteristic symptom cannot be explained by a Steele-Richarson disease, a multiple sclerosis or vascular lesions. Be aware of CNS involvement in pSS would leed to realise a minor salivary gland biopsy that is the only exam useful to establish the diagnosis.

\section{AB0119 PRIMARY SJOGREN'S SYNDROME ASSOCIATED WITH ANTERIOR HORN CELL DISORDER}

JC Tseng, HH Cheng, RJ Hu, LY Lu. Allergy, Immunology and Rheumatology, Veterans General Hospital, Kaohsiung, Taiwan, R.O.C

\subsection{6/annrheumdis-2001.302}

Background Central nervous system (CNS) involvement in primary Sjogren's syndrome (pSS) is controversial with regard to incidence, aetiology and pathogenesis. In the literature, the incidence of CNS-SS varies widely, ranging from rare to incidence rates of $20 \%$ to $25 \%$. The clinical picture is diverse, ranging from mild cognitive symptoms to fatal cerebrovascular accidents. Objectives We describe a patient with pSS presenting with dysphagia and progressive respiratory failure resulting from anterior horn cell disorder. To the best of our knowledge this is the first case reported in medical literature. The disease responded to corticosteroids and hydroxychloroquine treatment.

Methods A 58-year-old woman had a one year history of dry eyes and dry mouth. She experienced progressive dysphagia and dyspnea ten days prior to admission. She developed progressive respiratory muscle weakness which resulted in respiratory failure and received mechanical ventilation during admission. Examination revealed symmetrically decreased muscle power without sensory impairment and positive Schirmer test. Blood investigations revealed positive ANA, anti-SS-A and elevated IgG level up to $2820 \mathrm{mg} / \mathrm{dl}$. Full blood cell count and creatine kinase level were normal. Sjogren's syndrome was confirmed by minor salivary gland biopsy. Electromyography, nerve conduction velocity and evoked potential studies showed anterior horn cell disorder. MRI of brain revealed negative finding. The disease improved with administration of corticosteroids and hydroxychloroquine. Results
Conclusion Sjoren's syndrome should be considered in the differential diagnosis of patients with motor neuron diseases. Promop diagnosis and treatment are required to prevent further morbidity and mortality.

\section{REFERENCES}

1 Cox PD, Hales RE. CNS Sjogren's syndrome: an underrecognized and underappreciated neuropsychiatric disorder. J Neuropsychiatry Clin Neurosci. 1999;11 (2):241-7

2 Wright RA, O'Duffy JD, Rodriguez M. Improvement of myelopathy in Sjogren's syndrome with chlorambucil and prednisolone therapy. Neurology 1999;52 (2):386-8

3 Ioannidis JP, Moutsopoulos HM. Sjogren's syndrome: too many associations, too limited evidence. The enigmatic example of CNS involvement. Semin Arthritis Rheum. 1999;29(1):1-3

4 Niemela RK, Hakala M. Primary Sjogren's syndrome with severe central nervous system disease. Semin Arthritis Rheum. 1999;29(1):4-13

\section{AB0120 PRIMARY SJOGREN'S SYNDROME ASSOCIAED WITH ANTERIOR HORN CELL DISORDER}

JC Tseng, HH Cheng, RJ Hu, LY Lu. Allergy, Immunology and Rheumatology, Veterans General Hospital, Kaohsiung, Taiwan, R.O.C

\subsection{6/annrheumdis-2001.303}

Background Central nervous system (CNS) involvement in primary Sjogren's syndrome (pSS) is controversial with regard to incidence, aetiology and pathogenesis. In the literature, the incidence of CNS-SS varies widely, ranging from rare to incidence rates of $20 \%$ to $25 \%$. The clinical picture is diverse, ranging from mild cognitive symptoms to fatal cerebrovascular accidents. Objectives We describe a patient with pSS presenting with dysphagia and progressive respiratory failure resulting from anterior horn cell disorder. The disease responded to corticosteroids, hydroychloroquine and azathioprine treatment. To our knowledge this is the first case reported in the medical literature.

Methods A 58-year-old woman had a one year history of dry eyes and dry mouth. She experienced progressive dysphagia and dyspnea ten days prior to admission. She developed progressive respiratory muscle weakness which resulted in respiratory failure and received mechanical ventilation during admission. Examination revealed symmetrically decreased muscle power without sensory impairment. Schirmer test was positive. Blood investigations revealed positive ANA, anti-SS-A and elevated IgG level up to $2820 \mathrm{mg} / \mathrm{dl}$. Full blood cell count and creatine kinase level were normal. Sjogren's syndrome was proved by minor salivary gland biopsy. Electromyography, nerve conduction velocity and evoked potentials studies showed anterior horn cell disorder. MRI of brain revealed negative finding. The disease improved with administration of corticosteroids, hydroxychloroquine and azathioprine.

Results

Conclusion Sjogren's syndrome should be considered in the differential diagnosis of patients with motor neuron diseases. Prompt diagnosis and treatment prevent further morbidity and mortality.

\section{REFERENCES}

1 Cox PD, Hales RE. CNS Sjogren's syndrome: an underrecognized and underappreciated neuropsychiatric disorder. J Neuropsychiatry Clin Neurosci. 1999;11 (2):241-7

2 Wright RA, O'Duffy JD, Rodriguez M. Improvement of myelopathy in Sjogren's syndrome with chlorambucil and prednisolone therapy. Neurology 1999;52 (2):386-8

3 loannidis JP, Moutsopoulos HM. Sjogren's syndrome: too many associations, too limited evidence. The enigmatic example of CNS involvement. Semin Arthritis Rheum. 1999;29(1):1-3 